ISSN: 0213-2060

DOI: https://doi.org/10.14201/shhme2020381113139

\title{
REUBICAR LA RELIGIÓN ISLÁMICA: APROXIMACIÓN A LAS MEZQUITAS MUDÉJARES EN EXTREMADURA ${ }^{1}$
}

\author{
Relocating the Islamic Religion: Approach to Mudejars Mosques in Extremadura \\ Juan REBOLLO BOTE \\ Depto. de Historia Antigua y Medieval. Facultad de Filosofia y Letras. Universidad de Valladolid. Plaza Campus \\ Universitario, s/n.E-47011 VALLADOLID. C. e.: juan.rebollo@uva.es
}

Recibido: 2019-11-16

Revisado: 2020-03-10

Aceptado: 2020-05-04

RESUMEN: La permanencia de musulmanes en Extremadura tras la conquista cristiana del territorio durante la Baja Edad Media devino en la conformación de varias aljamas mudéjares en la región. Estas comunidades de moros hubieron de adaptarse a la nueva realidad política y social castellana y reubicarse en lugares urbanos distintos a los que habían ocupado durante la etapa andalusí. El conocimiento que vamos adquiriendo sobre sus morerías, sobre todo para finales del siglo xv, permite realizar un primer acercamiento a sus espacios de oración. Recopilamos aquí las noticias documentales sobre las mezquitas mudéjares extremeñas.

Palabras clave: Islam; Edad Media; Mudéjares; Mezquitas; Extremadura.

ABSTRACT: During the Low Middle Ages, after the Christian conquest of the Spanish region of Extremadura, several Mudejars aljamas were formed with the Muslims who opted for their permanence in the territory. These Moorish communities had to adapt to the new political and social reality of the Kingdom of Castile and had to relocate to different urban areas than they had occupied before. The knowledge that we are acquiring about their neighborhoods, especially at the end of the $15^{\text {th }}$ Century, allows us to do a first approach to their prayer spaces. We collect in this paper the documentary information about Mudejar mosques in Extremadura.

Keywords: Islam; Middle Ages; Mudejars; Mosques; Extremadura.

1 Este trabajo se inserta en el marco del Proyecto de Investigación ALM-Islam Estudio de los espacios rituales mudéjares en la Castilla medieval: Mezquitas y cementerios islámicos en una sociedad cristiana (HAR2017-83004-P), dirigido por la profesora Olatz Villanueva Zubizarreta (Universidad de Valladolid). 
SUMARIO: 0 A modo de introducción: reconsiderar el islam en Extremadura. 1 Mezquitas andalusíes: documentación y arqueología del paisaje ritual musulmán en la Extremadura altomedieval. 2 Mezquitas mudéjares: continuidad de poblamiento, nuevos espacios de oración islámica en la Extremadura bajomedieval. 2.1 La Orden de Alcántara. 2.1.1 Alcántara. 2.1.2 Valencia de Alcántara. 2.1.3 Magacela y Benquerencia de la Serena. 2.2 La Orden de Santiago. 2.2.1 Mérida. 2.2.2 Hornachos. 2.2.3 Llerena y otros lugares del maestrazgo santiaguista. 2.3 Realengo y seńorío laico. 2.3.1 Plasencia. 2.3.2 Trujillo y Cáceres. 2.3.3 Badajoz, Medellín y otros lugares de la Baja Extremadura. 3 A modo de conclusión: la revalorización de los espacios mudéjares. 4 Referencias bibliográficas.

\section{A MOdo DE INTROdUCCión: RECONSIDERAR EL ISLAM EN EXTREMADURA}

Poco a poco van fijando paso firme los estudios sobre historia islámica de Extremadura, tanto los que se circunscriben a la etapa andalusí en la región como los que abordan la minoría musulmana en época bajomedieval. Estos últimos han venido rellenando desde hace algunos ańos un importante hueco historiográfico que el mudejarismo peninsular había pasado por alto en su desarrollo desde el último tercio del siglo $\mathrm{XX}^{2}$. Los estudios históricos de ámbito local tampoco han abarcado tradicionalmente el fenómeno mudéjar extremeño, a diferencia de lo ocurrido con la minoría judía ${ }^{3}$. Sin embargo, no puede entenderse la realidad castellana y leonesa asentada en las cuencas medias del Tajo y el Guadiana si no se tiene en cuenta el pasado andalusí y la población autóctona que permaneció en sus tierras. Tampoco se alcanzaría a comprender la totalidad del mudejarismo ibérico obviando las características de las aljamas fronterizas situadas a caballo entre Portugal y Castilla. Además, las particularidades de las comunidades musulmanas establecidas en los maestrazgos de Alcántara y de Santiago, así como la singularidad de algunas de ellas, véase Hornachos, advierten igualmente de la necesidad de reconsiderar el islam en la región extremeña.

Pero, como decimos, nuevas investigaciones e hipótesis replanteadas en los últimos tiempos ofrecen un panorama cambiante y esperanzador que permite a su vez aproximarse a aspectos nunca abordados con anterioridad sobre el islam en Extremadura. En esta ocasión dirigimos nuestra atención a las mezquitas que existieron, o pudieron existir,

2 El profesor Ladero Quesada señalaba en 2010 que «sería útil recoger en un estudio conjunto todos los datos disponibles sobre los mudéjares de Extremadura»: LADERo QuesadA, Miguel Ángel. «Los mudéjares de Castilla cuarenta años después». En la España Medieval, 2010, vol. 33, pp. 383-424, aquí p. 390. Sus estudios sobre los mudéjares de Castilla son imprescindibles para adentrarse en el estudio de esta minoría: Los mudéjares de Castilla en tiempo de Isabel I. Valladolid: Instituto Isabel la Católica de Historia Eclesiástica, 1969; «Los mudéjares de Castilla en la Baja Edad Media». En Actas del I Simposio Internacional de Mudejarismo. Teruel: Centro de Estudios Mudéjares, 1981, pp. 339-390; o «Los mudéjares de Castilla en la Baja Edad Media». En Los mudéjares de Castilla y otros estudios de historia medieval andaluza. Granada: Universidad de Granada, 1989, pp. 11-132, entre otros.

3 Un somero estado de la cuestión sobre esta realidad historiográfica extremeña puede verse en Rebollo Bote, Juan. "Recuerdos, olvidos y distorsiones sobre "lo islámico" y "lo judío" en Extremadura". En XLVII Coloquios Históricos de Extremadura dedicados a la Universidad de Salamanca. Trujillo: Asociación Cultural Coloquios Históricos de Extremadura, 2018, pp. 475-502. 
en cada uno de los lugares donde se constituyeron aljamas de moros durante la Baja Edad Media ${ }^{4}$. Su estudio se encuadra en el más amplio marco de los espacios urbanos de identidad mudéjar que cristalizaron en Castilla -morerías, cementerios, carnicerías islámicas, etc. - y en el que la historiografía especializada ha puesto el foco recientemente ${ }^{5}$. En el caso extremeño, a la espera de proyectos arqueológicos que saquen a la luz nuevos hallazgos relacionados con el mundo mudéjar, hemos de contentarnos con las dispersas y escuetas referencias documentales que se guardan en los archivos. En el presente trabajo tratamos de mostrar y contextualizar cada una de esas noticias sobre los oratorios musulmanes con el fin de ir completando el esquema mudéjar de Extremadura.

4 Sobre las comunidades mudéjares en Extremadura, algunos trabajos destacados son los siguientes: para las aljamas de la Provincia de León de la Orden de Santiago, Rodríguez Blanco, Daniel. La Orden de Santiago en Extremadura en la Baja Edad Media (siglos XIV y XV). Badajoz: Editora Regional Extremeña-Diputación Provincial de Badajoz, 1985 (sobre las minorías religiosas, pp. 365-382); y sobre el caso concreto de Hornachos: Molénat, Jean Pierre. «Hornachos fin Xve-début Xvi e siècles». En la España Medieval, 2008 , vol. 31, pp. 161-176; Rebollo Bote, Juan. "Antes de "ser moriscos": datos e hipótesis sobre la etapa mudéjar de Hornachos». En X Jornadas de Historia de Almendralejo y Tierra de Barros, 2019, pp. 361-374; o ÍDEM. "La pervivencia de la identidad en las minorías: mudéjares y moriscos de Hornachos, Magacela y Benquerencia de la Serena». En Amrán, Rica y Cortijo Ocaña, Antonio (eds.). Jiménez de Cisneros: sus ideas y obras. Las minorías en España y América (siglos XV-XVII). Santa Barbara: Publications of eHumanista, 2019, pp. 120-132. Para las aljamas mudéjares de La Serena, además del trabajo anterior, Díaz GiL, Fernando. «Herederos de al-Asnām, aljamas de la Serena (siglos XIII-Xv)». En Actas de los III Encuentros de Estudios Comarcales Vegas Altas, La Serena y La Siberia. Magacela-La Coronada: Federación de Asociaciones Culturales de La Siberia, La Serena y Vegas Altas, 2010, pp. 87-107. Sobre Plasencia, MolénAt, Jean Pierre. «Alfaquíes anonymes dans la Castille des Rois Catholiques. Une affaire de succession entre moros d'Estremadure dans les dernières années du Xve siècle». En Echevarría Arsuaga, Ana (ed.). Biografías mudéjares o La experiencia de ser minoría. Madrid: Consejo Superior de Investigaciones Científicas, 2008, pp. 417-470; y Redondo Jarillo, M. ${ }^{a}$ Cristina. «La comunidad mudéjar de Plasencia durante el reinado de los Reyes Católicos». Medievalismo, 2013, vol. 23, pp. 291-341. Para Trujillo, pueden verse Ortego Rico, Pablo. «Elites y conflictividad en el seno de las aljamas mudéjares castellanas a fines de la Edad Media: exención tributaria y redes clientelares». Hispania, 2015, vol. 75, n. ${ }^{\circ}$ 250, pp. 505-536; у Reвоllo Bote, Juan. «La comunidad mudéjar de Trujillo: algunas características sobre su aljama y morería». En XLIII Coloquios Históricos de Extremadura. Trujillo: Asociación Cultural Coloquios Históricos de Extremadura, 2015, pp. 691-716. De carácter más general, Reвоllo Bote, Juan. "Morerías de Extremadura: espacios urbanos de vecindad islámica (mudéjar) a finales del siglo XV». Roda da Fortuna. Revista Eletrônica sobre Antiguidade e Medievo, 2015, vol. 4, n. ${ }^{\circ} 1$ 1-1, pp. 456-475; o ÍDEM. «En la frontera: el poblamiento islámico de Extremadura antes y después de la Raya con Portugal». En AmráN, Rica y Cortijo Ocaña, Antonio (eds.). Minorías en la España medieval y moderna: Asimilación y/o exclusión (siglos XV al XVII). Santa Barbara: Publications of eHumanista, 2018, pp. 61-75.

5 Sobre mezquitas mudéjares, a modo de contextualización, véase: MolÉnAT, Jean Pierre. «À propos des noms et des mosquées des vieux mudéjars de Castille après l'édit de février 1502». En De mudéjares a moriscos: una conversión forzada. Teruel: Instituto de Estudios Turolenses, 2003, vol. 1, pp. 543-554; y ORTEGO Rico, Pablo. "Cristianos y mudéjares ante la conversión de 1502. Mercedes a moros. Mercedes de bienes de moros». Espacio, Tiempo y Forma. Serie III, Historia Medieval, 2011, vol. 24, pp. 279-318. Para aspectos arqueológicos, JimÉnEz GADEA, Javier. «Espacios y manifestaciones materiales de los musulmanes castellanos: presencias y ausencias de una minoría medieval». Edad Media. Revista de Historia, 2016, vol. 17, pp. 67-95. 
Gracias a las labores arqueológicas que se vienen desarrollando en las últimas décadas, van dibujándose claros en el denso bosque andalusí extremeño, cada vez más y mejor definido. Aquí, de manera muy breve y esquemática, presentamos tan solo algunas de las mezquitas andalusíes de las que se tiene constancia certera o hipotética en la región.

El centro urbano más importante del suroeste peninsular a la llegada de los musulmanes en el siglo viII era Mérida y, como tal, esta ciudad debió ser el objetivo prioritario del nuevo poder árabe de cara a la islamización progresiva de toda la antigua provincia de la Lusitania. Es de suponer que la iglesia arzobispal emeritense, Santa María de Jerusalén, tornara a mezquita aljama ya en aquellos primeros momentos. La tradición, siguiendo la lógica urbanística de la Mérida tardoantigua, ha situado la catedral visigoda y luego mezquita andalusí en el lugar en que se estableció la iglesia de Santa María a partir del siglo XIII, en pleno centro de la ciudad romana. Aunque la arqueología no ha conseguido certificar esta superposición de templos, resulta razonable continuar manteniendo esta idea. Algo más documentada parece estar la mezquita situada en la alcazaba emeritense. Este oratorio, relativamente pequeño, se cimentaría sobre el pozo, llamado hoy aljibe, que abastecería de agua al recinto militar construido en el año 835 . Tras la conquista leonesa se convertiría en iglesia de Santa María del Castillo. Si hubo otras mezquitas en época omeya, es probable que desaparecieran con el tiempo, a juzgar por el retraimiento demográfico y urbanístico constatado por los arqueólogos para las etapas almorávide y almohade ${ }^{6}$.

Como contrapeso emeritense, tras su fundación a fines del Ix, Badajoz se constituyó en ciudad principal de la región occidental de al-Andalus a partir del Califato y se erigió como capital del reino de los Aftasíes en el siglo xi. En su alcazaba quedan restos de lo que el arqueólogo Fernando Valdés interpretó como la mezquita privada de Ibn Marwān, ampliada posteriormente, y que los cristianos readaptarían como catedral en el siglo XIII con el nombre de Santa María de la Sée 7 . Otras iglesias del Badajoz bajomedieval podrían haberse edificado sobre mezquitas islámicas, como Santa María de Calatrava o, ya fuera de la alcazaba, la de San Agustín (antes de San Lorenzo), pero no dejan de ser conjeturas más o menos fundamentadas. Es el caso de la iglesia de San Agustín, cuya torre presenta una fábrica de época precristiana que podría corresponderse con el alminar de una mezquita de cierta entidad ${ }^{8}$. Más allá de las pocas certezas de las que se dispone, el futuro

6 Feijoo Martínez, Santiago y Alba Calzado, Miguel Á. «El sentido de la Alcazaba emiral de Mérida: su aljibe, mezquita y torre de señales». Mérida. Excavaciones Arqueológicas, 2002, vol. 8, pp. 565-586; y Alba Calzado, Miguel Á.; Feijoo Martínez, Santiago y Franco Moreno, Bruno. "Mérida islámica (s. VIII-IX): El proceso de transformación de la ciudad tardoantigua en una medina». XELB: Revista de Arqueología, Arte, Etnología e Historia, 2009, vol. 9, pp. 191-228.

VAldés Fernández, Fernando. "La mezquita privada de 'Abd al-Rahman Ibn Marwan al-Yilliqi en la alcazaba de Badajoz». Cuadernos de Prehistoria y Arqueología de la Universidad Autónoma de Madrid, 1999, vol. 25, n. ${ }^{\circ}$ 2, pp. 267-290.

8 Valdés, Fernando; Gussone, Martin y Rütenik, Tobias. «Die Transformation von Sakralbauten in Spanien: Voraussetzungen, Beispiel San Agustin in Badajoz». Beiträge zur Islamischen Kunst und Archäologie, 2008, vol. 1, pp. 123-134. 
sí que podría deparar resultados en lo que a templos musulmanes se refiere, ya que la alcazaba badajocense tiene una importante potencia arqueológica aún poco explorada.

Fuera de las dos ciudades extremeńas comentadas el panorama se ensombrece bastante. Tan solo están documentadas arqueológicamente algunas mezquitas de carácter rural como, según indicio epigráfico, la de Las Paredes (Logrosán) ${ }^{9}$ o la del yacimiento del Castillo del Cuerno (Fuentes de León) ${ }^{10}$. También son interesantes las teorías del arqueólogo Víctor Gibello acerca de la iglesia de San Juan Bautista de Burguillos del Cerro, que podría haber actuado como ribat, o sobre el aljibe andalusí de Cáceres, readaptación hidráulica de un edificio ¿de oración? anterior ${ }^{11}$. Otras pistas sobre templos musulmanes nos las ofrece la toponimia histórica, como la Mezquiella documentada en el siglo XIII (Sierra de Gata), o la conservada hasta hoy, caso del Puerto de la Mezquita (Casas de Don Antonio). Sin embargo, otros nombres de origen árabe han dado pie a lo largo del tiempo a confusiones e interpretaciones erróneas por parte de eruditos locales que incluso se siguen teniendo por válidas en la actualidad. Lo que sí parece evidente, a pesar de no existir documentación escrita o arqueológica que lo pueda corroborar, es que muchas de las iglesias que tomaron la advocación de Santa María después de la conquista cristiana habrían sido mezquitas durante su etapa islámica ${ }^{12}$, como se percibe de los mencionados casos de Mérida y Badajoz y se deduce en Coria, Trujillo, Cáceres y otras plazas andalusíes de la región.

\section{Mezquitas mudéJares: continuidad de poblamiento, nuevos espacios de ORACIÓN ISLÁMICA EN LA EXTREMADURA BAJOMEDIEVAL}

La conquista leonesa y castellana de la actual Extremadura se llevó a cabo en varias fases a lo largo del siglo comprendido entre los años 1142 y 1248. La política que los reyes hispánicos promovieron en relación con la población autóctona fue dispar según la zona y el momento, pero en general primó la integración del colectivo musulmán en el seno de la sociedad cristiana mediante pactos de conquista. Se siguió la tónica establecida tras la conquista de Toledo de 1085, al menos en lo que a la parte castellana respecta, porque en el reino leonés no parecen haber proliferado aljamas de moros hasta bien entrado el siglo XIII. Eso es lo que apreciamos de la lectura de los fueros leoneses de Coria y

9 Gilotte, Sophie; González Cordero, Antonio y Souto Lasala, Juan Antonio. «L’inscription d'époque omeyyade de la mosquée de Las Paredes (Logrosán, Espagne)». Archéologie Islamique, 2000, vol. 10, pp. 55-64.

10 Franco Moreno, Bruno y Gibello Bravo, Víctor M. «La arqueología medieval en Extremadura. Estado de la cuestión». Boletín de Arqueología Medieval, 2012, vol. 16, pp. 67-120, aquí, pp. 87 y ss.

11 Bustamante, Rosa; Cabezas, M. a Teresa y Gibello, Víctor M. «Moldura de cal de los arcos de herradura del aljibe de la Casa de las Veletas de Cáceres, España». Revista Electrónica ReCoPaR, 2009, vol. 6, pp. 3-13.

12 Para Toledo y Sevilla, Bueno SÁnchez, María Luisa. «Fuga demonium, angeli pacis ingresus. El ritual litúrgico romano-galicano en el proceso de transformación de espacios sacros: de la mezquita a la iglesia (XI-XiII)». En Jiménez Martín, Alfonso (ed.). Simposium internacional sobre la catedral de Sevilla en el contexto del gótico final. La piedra postrera (2) Comunicaciones. Sevilla: Taller Dereçeo, 2007, pp. 261-280. 
REUBICAR LA RELIGIÓN ISLÁMICA: APROXIMACIÓN A LAS MEZQUITAS MUDÉJARES EN EXTREMADURA JUAN REBOLLO BOTE

Cáceres, donde las menciones a musulmanes se refieren únicamente a siervos o cautivos, pero no a moros libres o yenguos, como sí aparecen en el fuero de Plasencia ${ }^{13}$.

La excepción estaría en la parte leonesa del maestrazgo de Alcántara y, ya al albor de la unión de las coronas, en las más pobladas tierras del Guadiana, que en gran parte se constituirían en maestrazgo de Santiago. A mediados del siglo XII la demografía musulmana al norte del Tajo sería muy escasa, mientras que al sur de dicho río estaría concentrada principalmente en plazas militares de importancia como Alcántara, Trujillo o Cáceres. La presencia de mudéjares en Plasencia seguramente se debiera a la inmigración musulmana que se favoreciera en Castilla durante el reinado de Alfonso viII ${ }^{14}$.

Efectivamente, las comunidades mudéjares extremeñas de las que tenemos noticias ya para el mismo siglo XIII se corresponderían en gran medida (con la probable excepción de Plasencia) con los lugares de mayor entidad en época almohade, lo que nos permite asegurar que hubo continuidad de poblamiento islámico en la mayor parte de los casos, aunque no podemos descartar aportes demográficos posteriores, así como la manumisión de moros esclavos. Los musulmanes serían reubicados en áreas urbanas periféricas, mientras que las mezquitas aljamas y fortalezas andalusíes pasarían a manos cristianas. A partir de entonces se crearían nuevos espacios de identidad islámica, ahora mudéjar. La solidaridad y mejor organización socio-religiosa tendería a agrupar a la minoría en torno a las nuevas mezquitas, aunque esto no quiere decir que no vivieran entremezclados con cristianos. Prácticamente todas las informaciones que poseemos sobre mezquitas y morerías extremeńas proceden de documentación de la segunda mitad del siglo XV y principios del XVI, pero en algunos casos nos ofrecen datos útiles para periodos precedentes.

A continuación veremos aljama por aljama las referencias documentales que tenemos para conocer las mezquitas mudéjares en Extremadura. Hemos optado por dividir este apartado siguiendo un criterio de organización territorial del ámbito extremeño medieval que distingue entre dominios de la Orden de Alcántara, por un lado, los de la Orden de Santiago, por otro, y los de realengo y señorío laico, por último.

\subsection{La Orden de Alcántara}

Las zonas en las que se fijó el dominio de la Orden de Alcántara en Extremadura se caracterizaban por estar débilmente pobladas. De una parte, el noroeste de la provincia de Cáceres, donde solo Alcántara gozaba de cierta entidad al estar erigida para defensa estratégica de su puente romano. De otra parte, la comarca badajocense de La Serena, donde fortalezas almohades como Magacela o Benquerencia habían custodiado uno de los caminos que unían las Vegas del Guadiana con el Alto Guadalquivir. Estas plazas y alguna otra, como tal vez Valencia de Alcántara, aglutinarían la escasa población andalusí de aquellas áreas. Las autoridades cristianas no tendrían más remedio que pactar

13 Echevarría Arsuaga, Ana. "La "mayoría” mudéjar en León y Castilla: legislación real y distribución de la población (Siglos XI-XIII)». En la España Medieval, 2006, vol. 29, pp. 7-30, aquí, pp. 14 y ss.; Monterde García, Juan Carlos. «La cuestión islámica en el fuero de Cáceres». Revista de Estudios Extremeños, 2010, vol. 66, n. ${ }^{\circ}$ 3, pp. 1145-1170.

14 Rebollo Bote, «En la frontera: el poblamiento islámico de Extremadura», pp. 65 y ss. 
su permanencia, de no querer gobernar sobre territorios más yermos aún. En época de Sancho IV ya se citan las cuatro comunidades mudéjares del maestrazgo, que continuarán siendo las mismas aljamas a finales del siglo xv: Alcantara, Valençia, Magazella e Bienquerençia ${ }^{15}$.

Y precisamente ese rey, en 1285, y a petición del maestre alcantarino, exime de pechos a los moros de Alcántara, Magacela y Benquerencia ${ }^{16}$. Esta es la primera prueba que tenemos del trato de favor que caracterizará la política de los maestres de Alcántara para con los mudéjares de su señorío. En los siglos XIV y XV otras franquezas fiscales y privilegios de amparo y protección fueron otorgados a las diferentes aljamas ${ }^{17}$, sobre todo a las situadas en La Serena ${ }^{18}$, donde los musulmanes conformaban mayorías poblacionales. En 1501 la demografía mudéjar de las cuatro aljamas rozaba los tres centenares de familias pecheras, lo que, en el contexto urbano de Magacela, de Benquerencia y, en menor media, de Alcántara y Valencia, suponía una población considerable social y económicamente ${ }^{19}$. No es de extrañar, por tanto, que los maestres no fueran todo lo estrictos que debieran en el cumplimiento de órdenes como la de apartamiento de 1480.

\subsubsection{Alcántara}

En 1213, cuando los cristianos se apoderan definitivamente de Alcántara, su mezquita aljama mudaría a iglesia con la advocación de Santa María, luego conocida como de la Encarnación, dentro de la villa, es decir, en el espacio amurallado donde se encontraba la alcazaba y la medina andalusí2 ${ }^{20}$. Pero muy pronto la villa se expandiría hacia el este, sobre el lugar que ocupaba el cementerio musulmán, al-maqbara, puesto que se constata la existencia de la iglesia de Santa María del Almocóvar ya en la segunda mitad de siglo ${ }^{21}$. Por su parte, los moros que permanecieron en Alcántara se trasladarían, o serían trasladados, extramuros de la «villa vieja». No sabemos si el área donde a finales del siglo XV se documenta el barrio islámico ya lo era desde el mismo siglo XIII. De cercarse la morería, creemos que se hubiera hecho, al menos de manera rigurosa, una vez que el maestrazgo pasara a administración regia, a partir de 1494. Tampoco podemos certificar

15 Gaibrois de Ballesteros, Mercedes. Historia del reinado de Sancho IV de Castilla. Madrid: Tip. de la Revista de Archivos, Bibliotecas y Museos, 1922-1928, 3 vols.; aquí, Apéndice documental, p. CLXxIx.

16 Ibidem, p. ClXv. Ignoramos por qué no se cita o se exime a los moros de Valencia de Alcántara.

17 Ortego Rico, Pablo. «La imagen de la minoría islámica castellana a través de las fuentes fiscales a fines de la Edad Media». Edad Media. Revista de Historia, 2016, vol. 17, pp. 33-66, aquí pp. 61-65.

18 Díaz GiL, «Herederos de al-Asnām», pp. 95 y ss. y anexo documental.

19 Ladero Quesada, Los mudéjares de Castilla, p. 19. Todas las estimaciones demográficas que siguen sobre el colectivo mudéjar extremeño están calculadas con base en la documentación publicada en esta obra sobre la contribución fiscal de castellanos de oro.

${ }^{20}$ Martín Nieto, Serafín y Martín Nieto, Dionisio Á. «Edificaciones religiosas de la villa de Alcántara». En Noticias de Alcántara. Cáceres: Institución Cultural el Brocense, 2010, vol. 2, p. 245.

21 La tradición ha venido insistiendo, guiada por la mala lectura de Almocóvar, en su construcción sobre una antigua mezquita, pero una correcta interpretación y su situación extramuros del recinto amurallado andalusí hace presagiar que se superpone a un área de enterramientos islámicos, Ibidem, p. 270. 
REUBICAR LA RELIGIÓN ISLÁMICA: APROXIMACIÓN A LAS MEZQUITAS MUDÉJARES EN EXTREMADURA JUAN REBOLLO BOTE

su existencia hasta la visita de 1499, cuando, hablando de los musulmanes alcantarinos, se cita lacónicamente su arrabal2.

La morería de Alcántara se encontraba, en los últimos años de la era mudéjar, al oeste de la villa, limitada por la muralla, la puerta de San Juan y la calle Nueva (hoy Zapatería). Englobaba las calles Sancti Spíritus, seguramente también Ollerías y Cuco, y tal vez, al menos en parte, Cantarranas. Se ha de tener en cuenta que la aljama estaba constituida por unas 45-50 familias pecheras en 1495-1496 que llegarían hasta casi duplicarse en los últimos años del siglo a consecuencia del arribo de musulmanes procedentes de Portugal tras su expulsión en 1496-149723. Con la aljama alcantarina también pechaban, en 1491, los moros de Brozas y Ceclavín ${ }^{24}$, aunque el grueso de la comunidad se encontraría en Alcántara.

En relación con el hospital de Sancti Spíritus nos han llegado las únicas noticias que tenemos de la mezquita mudéjar de Alcántara. Los cofrades de Sancti Spíritus compraron en 1522 a Juana de Quirós el edificio que fuera oratorio musulmán, ya convertido en casa, que lindaba entonces con la casa de Miguel García ${ }^{25}$. Pedro Barrantes también da testimonio: los cofrades passaron el hospital a la mezquita que fue de los moros en la Calle $N_{u e v a^{26}}$. En la visita que realizaron las autoridades alcantarinas en 1526 se nos brindan algunos detalles del hospital que son de enorme interés de cara al reconocimiento de la mezquita. Seguimos la descripción ofrecida por Serafín y Dionisio Martín Nieto en las Noticias históricas de Alcántara:

La portada era de cantería y los muros de barro y piedra. Nada más acceder al interior, había un portal enladrillado a manera de patio con su pozo; y a mano derecha del zaguán se abría una portada de ladrillo revocada de falsa cantería que daba paso a una sala baja con poyos de piedra a su alrededor y un altar para colocar el Santísimo Sacramento cuando se llevaba la comunión a los pobres y a mano derecha la cámara donde se daba cobijo a los menesterosos. Por esta sala, donde se reunían los cofrades el día de Pascua de Pentecostés para la cáńama, se pasaba a una casa dotada de cuatro camas, que era el número de acogidos. En su corral, tenían pensado construir unas cuadras para guardar las caballerizas que trajeran los mendigos. Aún no se había edificado la iglesia ${ }^{27}$.

Estamos ante una descripción solo cuatro años posterior a la compra del inmueble por los cofrades de Sancti Spíritus en 1522. Como se nos cuenta, el hospital aún no tenía construido en 1526 ni la iglesia ni las caballerizas. Ha de tenerse igualmente presente que entre ese momento y la época en que fue oratorio musulmán habían pasado unos veinte años. Desconocemos las intervenciones reales que se acometieran en todo aquel tiempo,

22 Martín Nieto, Dionisio Á. «Panorama histórico de la villa de Alcántara en el siglo xvi». En Noticias de Alcántara. Cáceres: Institución Cultural el Brocense, 2010, vol. 2, p. 53.

23 Soyer, François. The persecution of the Jews and Muslims of Portugal: King Manuel I and the End of Religious Tolerance (1496-7). Leiden-Boston: Brill, 2007, pp. 263-265; Rebollo Bote, «Morerías de Extremadura», p. 467.

24 Archivo General de Simancas (AGS). Registro General del Sello (RGS), febrero de 1491, fol. 49.

25 Martín Nieto y Martín Nieto, «Edificaciones religiosas», pp. 472-473.

26 Martín Nieto, «Panorama histórico», p. 53.

27 Martín Nieto y Martín Nieto, «Edificaciones religiosas», p. 473. 
pero creemos poder reconocer algunas estructuras que hipotéticamente coincidieran con las del complejo religioso islámico. Así, el portal enladrillado con pozo que se menciona casaría con los patios de abluciones que se sitúan a la entrada de las mezquitas, si bien esta circunstancia es común en las estructuras domésticas de la época. De la misma forma, la sala baja con poyos de piedra en la que los cofrades habían colocado un altar podría corresponderse con la sala de oraciones, si nos dejamos guiar por la lógica de conversión de espacios religiosos. La casa en la cual se encontraban las cuatro camas del hospital bien pudiera haber sido el lugar restringido a la jerarquía religiosa, a modo de casa del alfaquí, atestiguada en otros lugares de Castilla ${ }^{28}$. Por último, también es habitual que parte del solar de las mezquitas mudéjares se destine a corrales.

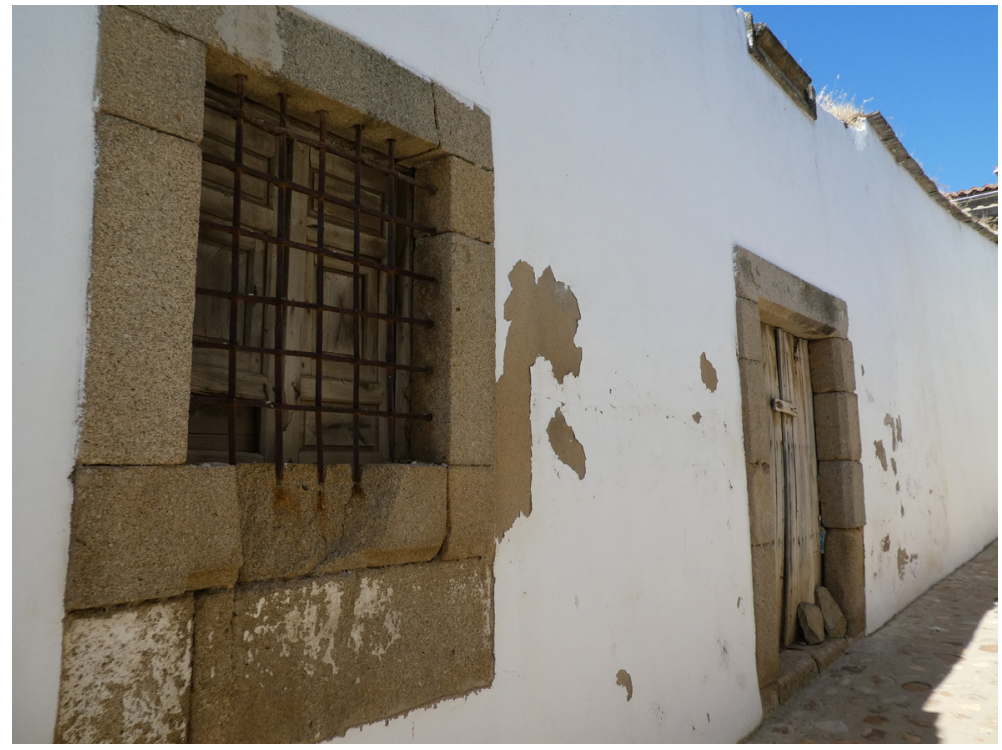

Figura 1. Portada y ventana pertenecientes al edificio del antiguo Hospital de Sancti Spíritus de Alcántara, en el solar que fue mezquita de los moros (fotografía: Juan Rebollo).

En la actualidad, el inmueble, aún en pie, pero en proceso de ruina, abarca una importante extensión de las actuales calles de Sancti Spíritus y Zapatería. Quizá la mezquita, antes de convertirse en la casa propiedad de Juana de Quirós, tuviera acceso y fachada tan solo por la calle Zapatería (antigua calle Nueva). Nada más podemos elucubrar hasta el momento. Insistimos, a sabiendas de la dificultad que entraña una interpretación como la expuesta y a la espera de otros documentos que arrojen más luz al respecto,

28 Junto a la casa de oración podrían encontrarse otros edificios cercanos o anexos a la misma, formando parte del complejo de la mezquita y destinados a oficios festivos o de la jerarquía religiosa, como la casa de bodas o la casa del alfaquí, documentadas en lugares como Valladolid; Villanueva Zubizarreta, Olatz. "Los mudéjares del norte de Castilla en vísperas del bautismo: expresiones religiosas de un Islam que no fue al-Andalus». eHumanista/Conversos, 2015, vol. 3, pp. 192-206, aquí p. 198-199. 
podría servir de hipótesis provisional, con toda la cautela en cuanto a las equivalencias propuestas. La única certeza es que la mezquita estuvo en aquel lugar. El estado de abandono que presenta el edificio debería ser aprovechado por las instituciones pertinentes, antes de que sea tarde, para el estudio de la que podría ser una de las pocas mezquitas mudéjares extremeńas todavía reconocible en mayor o menor medida.

\subsubsection{Valencia de Alcántara}

Otra de las aljamas del maestrazgo alcantarino que ya reseñan las fuentes del siglo XIII y que pervive hasta la fecha crítica de 1502 es la de Valencia de Alcántara, cuya pequeña comunidad de musulmanes acaso fuera continuadora del poblamiento andalusí asentado en el territorio estratégico entre Badajoz y Alcántara, si bien su origen también podría deberse al arraigo de moros procedentes de otras partes de Castilla o de Portugal, dado que la arqueología no ha confirmado antecedentes andalusíes del enclave. Solo a finales del siglo Xv podemos vislumbrar algunas características de la aljama mudéjar valentina, cuyo proceso histórico sería similar al de la vecina de la villa de Alcántara. De hecho, la llegada de moros portugueses en 1497 doblaría también la vecindad islámica de Valencia que pasaría de una quincena de familias a más de treinta en el lapso 1498-1501. La cercanía de la frontera sería determinante para el desarrollo de todos los habitantes de esta zona de la Raya y, como vemos, también para la minoría musulmana ${ }^{29}$. Más allá de datos fiscales y alguna mención suelta en las ordenanzas del concejo, poco más hemos podido recoger sobre los mudéjares valentinos.

Sin embargo, la pervivencia del topónimo Mezquita en su callejero nos puede procurar alguna idea sobre su lugar de asentamiento en la villa. Se trata de una calle sin salida que se encontraba deshabitada a la altura de $1732^{30}$, que es cuando su nombre se documenta por primera vez. Según la tradición, el paraje de la mezquita se correspondería con la parte trasera de la casa número 18 de la calle Cortizada y en un solar contiguo había un patio con dos pozos que podrían estar en relación con el complejo ${ }^{31}$. El final de la calle Mezquita coincide, grosso modo, con las traseras de los citados solares de la Cortizada, calle en gran parte paralela a la anterior y donde también la tradición sitúa el espacio de vecindad islámica, pero nuestro estado de conocimiento no nos permite aventurarnos más. De otro lado, la idea según la cual las columnas que se encuentran en el interior del ayuntamiento valentino procederían de una antigua mezquita, como se dice expresamente en un cartel informativo en la portada-soportales con columnas árabes de una mezquita del siglo XIII-, no parece tener fundamento alguno.

\footnotetext{
29 Rebollo Bote, «En la frontera: el poblamiento islámico de Extremadura», pp. 70 y ss.

30 Galavís Bueno, Francisco. Consideraciones sobre el Barrio Gótico de Valencia de Alcántara. Badajoz: IMDEX Impresores, 2010, pp. 324 y 326.

$31 \quad$ Ibidem, p. 326.
} 


\subsubsection{Magacela y Benquerencia de la Serena}

Las otras dos localidades pertenecientes al maestrazgo de Alcántara con presencia musulmana durante toda la Edad Media fueron las de Magacela y Benquerencia de la Serena, ya en la actual provincia de Badajoz. Estas plazas habían sido incorporadas a Castilla respetando sus demarcaciones territoriales de época andalusí y la permanencia de sus pobladores musulmanes, seguramente mediante capitulación ${ }^{32}$. La particularidad radica en este caso en que la comunidad islámica conformaba la mayoría demográfica de ambas poblaciones a finales del siglo Xv, unas 80 familias pecheras cada una ${ }^{33}$. Esta circunstancia, unida al gobierno benefactor de Juan de Zúñiga, primero como maestre de Alcántara y después como abad de La Serena hasta su muerte en 1504, descartaría con toda seguridad la aplicación de la orden de segregación dictada por los Reyes Católicos. A pesar de su considerable importancia sociodemográfica a nivel local, no tenemos noticias documentales o arqueológicas de mezquitas en ninguno de estos pueblos, aunque, sin duda, hubieron de existir. La pervivencia de las prácticas islámicas, así como el uso de la lengua árabe, está bien atestiguada en las dos villas serenenses según informes inquisitoriales del siglo $\mathrm{XvI}^{34}$.

\subsection{La Orden de Santiago}

Al contrario que en la jurisdicción alcantarina, en las tierras de la Orden de Santiago la población mudéjar se encontraba mucho más repartida a finales de la Edad Media. Rodríguez Blanco documentó musulmanes en casi una veintena de lugares del partido de Mérida y otros tantos en el de Llerena ${ }^{35}$. Esto concuerda con la sucinta referencia que tenemos para la época de Sancho IV, cuando se nos dice que hay comunidades islámicas, además de las ya apuntadas en el maestrazgo de Alcántara, en Fornanches e otros logares de las ordenes ${ }^{36}$, poniéndonos sobre aviso de la pronta significancia de la aljama de Hornachos en el señorío santiaguista, así como de la dispersión del resto de grupos mudéjares por el mismo. Las otras dos aljamas que se constituyeron fueron las de Mérida y Llerena. En los últimos años del siglo xv más de la mitad de los mudéjares extremeños residían en dominio santiaguista debido fundamentalmente al peso demográfico hornachero.

También se debería, por un lado, a la continuidad de parte del poblamiento musulmán en la Baja Extremadura, más y mejor poblada que el norte extremeño en época andalusí gracias a la fertilidad de sus tierras. La política de pactos de conquista entre la toma de Mérida (1230) y la de Montemolín (1246) se dio, además, en un contexto

32 Díaz Gil, «Herederos de al-Asnām», pp. 91 y ss.; Rebollo Bote, «La pervivencia de la identidad en las minorías», pp. 124-128.

33 Ladero Quesada, Los mudéjares de Castilla, p. 19.

34 AGS. Consejo Real de Castilla, Leg. 60, fols. 45r-48r; y Leg. 60, fols. 49r-52r. Informes publicados en Miranda Díaz, Bartolomé y Córdoba Soriano, Francisco de. Los moriscos de Magacela. Magacela: Ayuntamiento de Magacela, 2010, pp. 221-231.

35 Rodríguez Blanco, La Orden de Santiago en Extremadura, p. 366.

36 Gaibrois de Ballesteros, Historia del reinado, p. ClXxix. 
REUBICAR LA RELIGIÓN ISLÁMICA: APROXIMACIÓN A LAS MEZQUITAS MUDÉJARES EN EXTREMADURA JUAN REBOLLO BOTE

de mayor necesidad y predisposición a la integración de la población autóctona en los esquemas cristianos. Y, por otro lado, a la atracción demográfica que, de un modo u otro, ejerció la Provincia de León de la Orden de Santiago en los últimos compases medievales. Los grandes maestres promoverían la fijación y el establecimiento poblacional en sus dominios, concediendo, como en las tierras alcantarinas, ventajas fiscales y otros privilegios. La protección de los maestres haría más atractivos los maestrazgos que ciertos lugares de realengo, como Badajoz, donde las minorías religiosas estaban más expuestas a las agresiones de las oligarquías locales. Como en Alcántara, en Mérida y en Llerena la pragmática de encerramiento tardaría en completarse. Como en Magacela y en Benquerencia, en Hornachos no se efectuaría la orden por la condición hegemónica de la población mudéjar en la localidad.

\subsubsection{Mérida}

A comienzos del siglo XiII, Mérida no era más que el esqueleto de la gran ciudad que había sido en época antigua y tardoantigua. Su espacio urbano se había reducido a una tercera parte de lo que fue la civitas romana (el pomerium) y el aspecto ampuloso de sus foros, templos y edificios de espectáculos había dado paso a una plaza militar representada por su alcazaba islámica y por su cerca defensiva y fosos. El islam era invocado en al menos dos mezquitas, una situada en el interior de la alcazaba y otra, previsiblemente la aljama, en el centro de la retraída urbe andalusí. Con la conquista de 1230, los leoneses ocuparían aquellos enclaves militares y religiosos, cristianizarían los dos oratorios islámicos con la advocación a Santa María, restaurarían la devoción a Santa Eulalia de Mérida y reubicarían fuera de la muralla a los musulmanes que optaron por la permanencia.

El lugar escogido como establecimiento para la minoría mudéjar se hallaba en una zona extramuros, cercana a la alcazaba y al río Guadiana, ocupada hasta unos siglos antes por construcciones romanas, tardoantiguas y altomedievales que en algún momento de entre los siglos XI y XII fue arrasada y reutilizada como espacio funerario islámico ${ }^{37}$. El nuevo arrabal se desarrolló a la vera de dos caminos que conectaban con el puente romano, uno que se internaba en el recinto emeritense franqueando la llamada Torre de los Ossos (que debería su nombre al osario cercano) y otro que comunicaba con la parte noroccidental de la ciudad (luego calle pública del rey, hoy calle Morerías). Sin embargo, el desarrollo de este suburbio sería transitorio, ya que las guerras y las epidemias que asolaron Mérida en el siglo XIV causaron su despoblación y casi total abandono. Sería en la segunda mitad del siglo xv, y particularmente tras el fin de la guerra civil castellana, cuando de nuevo se atisba la recuperación de este sector urbano emeritense ${ }^{38}$. Coincide este momento con la promulgación del edicto de apartamiento de las minorías en Castilla (Cortes de Toledo, 1480), aunque en Mérida, como en otros lugares de los maestrazgos

37 Alba Calzado, Miguel. «Ocupación diacrónica del área arqueológica de Morería (Mérida)». Mérida. Excavaciones Arqueológicas, 1994-1995, vol. 1, pp. 285-316, aquí, p. 296.

38 Alba Calzado, Miguel. «Evidencias arqueológicas y fuentes escritas sobre el barrio alfarero de Mérida durante los siglos xv, XVI y XVII». En Actas das IV Jornadas de cerámica medieval e pos-medieval. 2008, pp. 143-155. 
extremeños, no hay evidencias de un estricto acatamiento hasta los últimos años del siglo, una vez se encontraba ya bajo administración regia. Es lo que se deduce del hecho de que todavía en 1497 un cristiano posea una casa en la morería, año en que la vende a un moro ${ }^{39}$.

En el caso de que el barrio moro quedase finalmente cercado en aquellos ańos finales de siglo, algo de lo que no estamos seguros, su demarcación hipotética seguiría la línea de muralla romana -reconstruida en el siglo xv para integrar el arrabal- hasta unirse en algún punto con la puerta de San Salvador, dejando extramuros la necrópolis mudéjar. Continuaría su delimitación apoyándose quizá en los restos y el recuerdo de la cerca de época andalusí, dejando de la parte «cristiana» la actual calle de San Salvador, hasta llegar a la actual plaza de Roma (Loba Capitolina). El principal eje viario, la actual calle Morerías, podría haber unido postigos de acceso al barrio. Este espacio urbano albergaría la gran mayoría de la aljama de Mérida, compuesta de un centenar de familias pecheras c $1500^{40}$, a las que habría que añadir cierta cantidad de musulmanes no pecheros. Fuera de la morería, bajando hacia el Guadiana, se desarrollaría el barrio y la calle de Tenerías.

Si hay alguna ciudad extremeña donde la arqueología puede brindarnos datos para reconocer los espacios mudéjares, esa es Mérida. Las excavaciones del área de Morerías en los años 90 del siglo pasado sacaron a la luz importantes restos que podemos relacionar con el colectivo islámico. Por un lado, se excavaron una serie de hornos alfareros, en torno a una decena, que actuaban en la mayor parte de los casos también como vivienda ${ }^{41}$. Aunque el arqueólogo Miguel Alba no encontró pruebas evidentes de su identificación con los musulmanes, el hecho de que muchos alfares se construyan en el siglo XV en plena morería, sabiendo además la importancia que esta actividad tenía para la minoría en otros lugares de Extremadura y Portugal, nos lleva a plantear una relación lógica con los mudéjares. Durante el siglo XVI, y hasta bien entrado el XVII, la arteria principal del barrio aparece referida en la documentación tanto con el nombre de olleros/ollerías como con el de moros/morería ${ }^{42}$. De otro lado, hacia el otro extremo de la zona arqueológica apareció una gran concentración de sepulturas islámicas, cuya cronología inicial se remontaba a la etapa andalusí, pero que siguió en uso hasta la conversión de los mudéjares en 1502. Después de esta fecha al lugar de la maqbara se trasladará el Corral del Concejo ${ }^{43}$.

Sobre la mezquita sabemos que tras el edicto de conversión pasó a ser propiedad de la iglesia de Santa María de Mérida, que la puso en venta en 1503: una casa de oraçion que los moros tenian en esta çibdat la qual es hazia el rio y tiene un corral delante y una casyta del santero e un cuerpo de casa de una nave buena con su salida al rio e tejado e aderesçado

39 Archivo Municipal de Mérida (AMM), Leg. 2, núm. 20, s. f.; en Rodríguez Blanco, La Orden de Santiago en Extremadura, p. 375.

40 Ladero Quesada, Los mudéjares de Castilla, p. 19.

41 Alba Calzado, Miguel. "Las producciones alfareras alentejano-extremeñas durante el Antiguo Régimen». Mérida. Ciudad y Patrimonio. Revista de Arqueología, Arte y Urbanismo, 1997, vol. 1, pp. 79-107, aquí, pp. 87-91.

42 Alba Calzado, «Evidencias arqueológicas», p. 148.

43 AMM, Acuerdos 1503, fol. 20v; en Bernal Estévez, Ángel. Mérida. Capital y encomienda de la Orden de Santiago (1490-1530). Badajoz: Diputación Provincial de Badajoz, 2013, p. 126. 
muy bien ${ }^{44}$. También aquí la casyta del santero pudiera haber ejercido anteriormente de casa del alfaquí. Años después, todavía en posesión de Santa María, se nos dice que las casas que solya ser mesquita que es en la dicha çiudad en la morería que solía ser es linde de casas de Pedro de Trujillo e la çerca de la dicha çiudad ${ }^{45}$. Toda esta información permite intuir el antiguo oratorio islámico en la zona ya excavada de Morerías, a pesar de que los arqueólogos no han conseguido dar con sus restos. Las pistas documentales insisten en su proximidad a la cerca y dejan entrever la comunicación más o menos directa con el río Guadiana, quizá a través de un portillo abierto en la misma línea de muralla (hoy paralela al paseo de Roma). En el siglo Xvi uno de los portillos más transitados de la muralla emeritense era designado como el de las Tenerías, que podría corresponder con el que diera acceso a la morería por la zona de la mezquita. De momento, esto es todo lo que tenemos registrado, sin olvidar la posibilidad de que las bolas que coronan a modo de yamur islámico la torre del convento de Santa Clara de Mérida pudieran proceder de alguna mezquita de la ciudad, ya andalusí, ya mudéjar.

\subsubsection{Hornachos}

Es de sobra conocida la relevancia demográfica de la comunidad mudéjar de Hornachos en el conjunto de la Corona de Castilla. Los castellanos de oro nos dan entre 425 y 432 vecinos pecheros, mientras que los visitadores de la Orden de Santiago redondean la cifra a 600 para el mismo periodo de finales del $\mathrm{xv}^{46}$. La explicación ante tal desajuste nos la ofrece el Libro de Visita de 1494 que nos dice que dieron por copia jurada los alcaldes e oficiales moros de Hornachos que biven en ella quatroçientos e çinquenta e ocho moros pecheros e que de pobres, biuadas e venedesos ay otros çient vecinos ${ }^{47}$. Es decir, además de los contribuyentes, en este caso 458 familias $^{48}$, la aljama hornachega tenía en torno a 100 vecinos no pecheros, cuya suma al alza daría los 600 que apuntan los visitadores muy a la ligera. De cualquier modo, estamos hablando de una concentración de 2.000-2.500 mudéjares. El edicto de apartamiento no tendría efecto alguno. Toda la villa era una morería.

Hasta el reinado de los Reyes Católicos no comenzaron a establecerse familias cristianas en Hornachos. En la citada visita de 1494 se dice que los dichos visitadores fueron a la dicha villa de Hornachos e despues de visitada la fortaleza e la persona del comendador non hallaron que avia enla dicha villa nin en su termino yglesia nin hermita porque todos son moros salvo una capilleja pequeña que está en la fortaleza en que oyen misa el comendador e los suyos ${ }^{49}$. Será a partir de principios del siglo XVI, una vez convertida teóricamente la po-

44 Archivo Histórico Nacional (AHN). OM, Visitación de 1503, Ms. 1106, fol. 224.

45 AHN. OM, Visitación de 1508, Ms. 1107, fol. 212; y AHN. OM, Visitación de 1511, Ms. 1108, fol. 444 .

46 Rodríguez Blanco, La Orden de Santiago en Extremadura, p. 371.

47 AHN. OM, Visitación de 1494, Ms. 1101, fol. 582.

48 Para el ańo siguiente, 1495, los castellanos de oro arrojan la cifra de 432 vecinos (Ladero QueSADA, Los mudéjares de Castilla, p. 19), siendo la diferencia de un año para otro de 26 familias menos, lo que nos resulta, de momento, difícilmente explicable.

49 AHN. OM, Visitación de 1494, Ms. 1101, fol 158. 
blación mudéjar, cuando se dé una "activa vida constructiva» en la villa con la edificación de cuatro iglesias, una ermita, un convento y otras construcciones públicas ${ }^{50}$. Hasta entonces, la vida religiosa hornachega era esencialmente musulmana y, como tal, precisaría de mezquitas para su actividad devocional.

Ahora bien, ¿cuántos oratorios necesita una comunidad de más de dos millares de creyentes? La pregunta no es sencilla de responder. Dependería, en última instancia, del tamańo de cada templo. Pero si nos dejamos guiar por las cuatro iglesias que se construyen en la localidad tras el decreto de conversión, podemos hacernos una idea aproximada. Cierto es que una de aquellas iglesias fue la de Santiago, la antigua capilleja pequeña en la fortaleza. Podríamos reducir entonces a tres el hipotético número de mezquitas fornacenses. Sirva de apoyo a esta figuración el argumento de que Ávila, la segunda aljama más numerosa de Castilla, dispuso en algún momento de dos mezquitas coetáneas para la mitad de musulmanes de los que residían en Hornachos. No resulta arriesgado, por tanto, creer que existieran en la villa extremeńa más de dos oratorios musulmanes, sobre todo cuando disponía en 1501 de hasta una veintena de alfaquíes ${ }^{51}$.

Estas conjeturas son obligadas ante el lamentable silencio que guardan las fuentes en lo que respecta a mezquitas en Hornachos. Solo una noticia, muy tardía, sugiere que el pósito de la localidad, hoy Centro de Interpretación de la Cultura Morisca, actuara como oratorio en tiempos mudéjares ${ }^{52}$. Se trata de una idea expresada por el erudito local Ortí de Thovar en el siglo Xvin que, sin embargo, parece poco factible a juzgar por las características del edifico y su uso como almacén de grano desde el siglo XVI. La enorme ignorancia sobre esta cuestión en un lugar con un pasado islámico tan marcado, más allá de la parquedad documental, se debe también al arrasamiento ordenado por Carlos $\mathrm{V}$ en 1526 de la parte más antigua de la villa, entre la fortaleza y el actual vecindario. Si en un futuro se interviniera arqueológicamente en esa zona, posiblemente aparecerían restos y estructuras relacionadas con el urbanismo islámico de Hornachos y, por consiguiente, con alguna de las varias mezquitas que con seguridad hubiera en la mayor población mudéjar de Castilla.

\subsubsection{Llerena y otros lugares del maestrazgo santiaguista}

Probablemente, la aljama de Llerena aglutinase los musulmanes herederos de los emplazamientos andalusíes de Reina, Montemolín y otros cercanos, aunque la mayor parte de las familias islámicas, en torno a una cuarentena de pechas en $1495-1501^{53}$, habitarían en la misma villa llerenense, centro político santiaguista muy pujante a finales de la Edad Media. La morería se situaba en las cercanías de la iglesia de Santiago, siguiendo

50 Mogollón Cano-Cortés, Pilar. «Los alarifes moriscos y las realizaciones mudéjares en la villa de Hornachos». En Actas del IX Simposio Internacional de Mudejarismo. Mudéjares y moriscos, cambios sociales y culturales: Teruel: Instituto de Estudios Turolenses-Centro de Estudios Mudéjares, 2004, pp. 243-254.

51 MolÉnAT, «Hornachos fin Xve-début XVI ${ }^{\mathrm{e}}$ siècles», pp. 165-166.

52 González Rodríguez, Alberto. Hornachos, enclave morisco. Peculiaridades de una población distinta. Mérida: Editora Regional de Extremadura, 1990, pp. 111-114.

53 Ladero Quesada, Los mudéjares de Castilla, p. 19. 
REUBICAR LA RELIGIÓN ISLÁMICA: APROXIMACIÓN A LAS MEZQUITAS MUDÉJARES EN EXTREMADURA JUAN REBOLLO BOTE

las actuales calles de Gazul de Uclés y Morería y Herreros, donde intuimos se encontraría la mezquita. Los datos de los que disponemos, obtenidos principalmente de los Libros de Visita de la Orden de Santiago, no mencionan el oratorio mudéjar, pero nos aportan información acerca de los problemas que acarreó el decreto de reclusión. En 1494 los visitadores mandan a los moros llerenenses cerrar puertas y ventanas desde las cuales miraban y burlaban los oficios que se celebraban en la susodicha iglesia de Santiago y ordenan a los cristianos que aún viven en la morería que salgan de ella, advirtiéndonos, al igual que veíamos en Mérida, del incompleto cumplimiento del apartamiento todavía catorce años después del mandato ${ }^{54}$.

En otras localidades santiaguistas importantes como Jerez de los Caballeros, antiguo dominio de la Orden del Temple, también conocemos la zona de asentamiento mudéjar gracias a la pervivencia del nombre de la calle Morería, pero las fuentes consultadas callan sobre la historia local de la minoría. En el partido de Llerena, además de en la propia villa capital y en Hornachos, se registran moros en una quincena de lugares más ${ }^{5}$. En el de Mérida, casi en una veintena de ellos ${ }^{56}$, más concentrados en los alrededores de la ciudad emeritense, en el entorno de Montánchez y en la Tierra de Barros, destacando algunos pueblos como Ribera del Fresno, muy cerca de Hornachos, pero cuyos musulmanes tributan en 1477 con la vecina villa señorial de Burguillos. Otras pistas mudéjares nos son proporcionadas después de la conversión de 1502, por ejemplo, en Montijo donde se habla de dos convertidos moros que fueron entregados al cura para que toviese a cargo de los doctrinar e ynponer en cosas de la fe $e^{57}$. En ninguno de estos sitios hemos logrado documentar ecos urbanos de la población islámica.

\subsection{Realengo y señorío laico}

Aunque el fenómeno del mudejarismo extremeño está muy vinculado a los dominios de las Órdenes Militares, también hubo aljamas en territorios de realengo y en algún que otro señorío laico. Ciudades realengas como Trujillo o Cáceres fueron puntualmente objeto de deseo de la nobleza castellana, mientras que Plasencia o Medellín sí que llegaron a otorgarse de manera efectiva y prolongada a los Zúńiga y a los Portocarrero-Pacheco, respectivamente. Esta circunstancia jurisdiccional afectaba de lleno a las minorías. En lugares bajo jurisdicción regia la protección del rey se presentaba lejana y, por tanto, judíos y musulmanes estaban expuestos a la agresividad de la aristocracia local. En los lugares de señoríos quedaban, para bien o para mal, a expensas del señor. Las órdenes emanadas de las Cortes tendrían una implantación más rigurosa en el realengo que en el señorío.

54 AHN. OM, Visitación de 1494, Ms. 1101, fols. 572-576.

55 Rodríguez Blanco, La Orden de Santiago en Extremadura, p. 366.

56 Ibidem.

57 AHN. OM, Visitación de 1503, Ms. 1106, fols. 257-258. 


\subsubsection{Plasencia}

No es sencillo precisar el origen de la población mudéjar de Plasencia. Recientes estudios, apoyados en las últimas investigaciones arqueológicas en la ciudad, abogan por la existencia de un núcleo musulmán -llamado Amrus/Ambroz- anterior a la (re)fundación de la plaza por Alfonso VIII en torno a $1186^{58}$. Manteniendo como muy viable esta teoría, consideramos, sin embargo, que el enclave fortificado no dispondría entonces de un contingente moro significativo. De hecho, la presencia de musulmanes al norte del Tajo extremeño a partir de la conquista de Coria y de la despoblación de Albalat -c 1142- sería muy exigua, cuando no nula, y apenas habría sobrevivido alguna generación al avance castellano y leonés. Los núcleos habitados en la Alta Extremadura durante la segunda mitad de aquel siglo XII corresponderían en su inmensa mayoría a colectivos cristianos, autóctonos o alóctonos, arabizados o no, dedicados a actividades pastoriles o al pillaje y que serían progresivamente integrados en las estructuras políticas y sociales de León y de Castilla ${ }^{59}$. Nos referimos, en todo caso, a la práctica inexistencia de población islámica libre, es decir, mudéjares, y no a la presencia, más factible en aquellos momentos, de musulmanes siervos o cautivos.

Los mudéjares que se intuyen en el fuero placentino, al igual que los judíos, refieren con seguridad a una política de repoblación que lleva a cabo Alfonso VIII en Castilla, reino al que pertenece Plasencia, y de la que serán consecuencia muchas aljamas de la cuenca del Duero. Esta comunidad mudéjar altoextremeña se percibe también en la mención a las morerías del obispado placentino en tiempos de Sancho IV ${ }^{60}$. El primer apartamiento de las minorías ordenado por Catalina de Lancaster en 1412 afectó en Plasencia a los judíos, recluidos en la zona de la Mota ${ }^{61}$. Nada se nos dice acerca de la población islámica, pero, como ocurrió en otras ciudades castellanas de jurisdicción realenga, caso de Valladolid, pensamos que los mudéjares seguirían el mismo destino que sus vecinos hebreos, aunque desconocemos del todo su confinamiento.

La condición realenga de Plasencia perdura hasta que en 1442 se da en señorío a los Estúñiga, luego Zúñigas, que la mantendrán hasta 1488. De esta etapa señorial nos ha llegado la primera noticia sobre la mezquita mudéjar. En concreto, la cita se inserta en el Libro de Actas del Ayuntamiento, a fecha de 1463, donde, hablando del corral del concejo, se señala que esta çerca del meson que es al arraval de la dicha çibdat que es de la

58 Lora Serrano, Gloria. Ambroz, Ambrosía, Plasencia. Los nombres de una ciudad de la España medieval. Plasencia: Centro de Iniciativas y Turismo de la Comarca de Plasencia, 2016.

59 Rebollo Bote, Juan. «Espacios de nadie y de todos: Territorio y sociedad en la frontera andalusí al norte del Tajo extremeño (siglos viII-XI)». Vegueta. Anuario de la Facultad de Geografía e Historia, 2015, vol. 15 , pp. 185-209.

${ }_{60}$ López Dapena, Asunción. Cuentas y gastos (1292-1294) del rey D. Sancho IV el Bravo (1284-1295). Córdoba: Monte de Piedad y Caja de Ahorros de Córdoba, 1984, p. 199.

61 Hervás, Marciano de (Seudónimo de Marciano Martín Manuel). Historia de los judios de Plasencia y su tierra. I, De los orígenes a la Inquisición. Siglos XII-XVIII. 2. a ed. Sevilla: Medios Audiovisuales (Libro electrónico), 2009, p. 31 y ss. 
una parte las olleras e de la otra parte la mesquita de los moros ${ }^{62}$. Esta alusión es de mucho interés porque nos ubica el templo islámico fuera de los límites murarios placentinos, a pesar de que gran parte de los vecinos mudéjares residen en la misma época en el interior de la ciudad, en torno a la calle Talavera y la plaza Mayor ${ }^{63}$. El que la mezquita estuviera emplazada en el arrabal tal vez debamos interpretarlo como reminiscencia del hipotético apartamiento de principios del siglo xv que, en cualquier caso, al igual que pasó con los judíos, habría sido efímero.

La orden de reclusión dictada en 1480 reducía el espacio de hábitat mudéjar a las calles Vinagra, Patalón, posiblemente Morenas y tal vez alguna otra, todas cercanas a la zona de residencia tradicional de los musulmanes placentinos ${ }^{64}$. En 1495, Mahomad y Abrayn Vinagre se quejan ante el corregidor por la escasez de casas en la morería ${ }^{65}$ para una comunidad que entonces rondaría las ochenta familias (pecheras) ${ }^{66}$. No obstante, disponemos de información acerca de casas de moros también fuera de aquellas calles, si bien próximas, que nos inducen a pensar en una especie de «morería abierta». Desconocemos si el nuevo decreto conllevó la construcción de una nueva mezquita en el interior de la morería.

Los siguientes documentos que se refieren a ella, posteriores a la conversión, tan solo nos relatan las vicisitudes que acarreó la donación de los bienes mudéjares a Pedro de Alderete, pero nada se observa sobre la situación del templo: la mezquita e piedra del Onsario e casa de carneçeria e de una casa pequenna con un pozo que está junto con la dicha mezquita e de otras dos casas que son cabo los mesones de La Corredera de la dicha çibdad de Plasencia que los que heran moros, vecinos de la dicha çibdad, tenyan ${ }^{67}$. De esta información, además de saber que junto a la mezquita había una "pequeña casa con pozo", podemos extraer que a los musulmanes pertenecieron dos casas que se encontraban cerca de los mesones de La Corredera (aproximadamente la actual avenida Calvo Sotelo), pero no que el oratorio estuviera en la misma zona. La tradición placentina ha mantenido la idea de que la mezquita de los moros estuvo en el sitio que fue luego ermita de Santo Tomé, extramuros, en el barrio del Toledillo, cercano a la antigua Corredera. Sin embargo, las excavaciones arqueológicas que se llevaron a cabo hace unos ańos en el solar no fueron concluyentes sobre su hipotético pasado islámico ${ }^{68}$.

Aunque nuestro estado actual de conocimiento no nos permite establecer con claridad el lugar exacto de la mezquita, sí podemos afirmar que existió, al menos en los años 60 del siglo xv, un templo mudéjar en el arrabal placentino, junto a las ollerías de la ciudad, esto es, en algún punto entre la otrora corredera y el río Jerte. Si hubo otra

62 Archivo Municipal de Plasencia (AMP). Libro de Actas del Ayuntamiento, 28 de enero de 1463, fols. $15 \mathrm{v}$ y 16 .

${ }_{63}$ Sánchez Loro, Domingo. Historias placentinas inéditas. Primera parte. Vol. B. Cáceres: Institución Cultural El Brocense, 1983.

64 Redondo Jarillo, «La comunidad mudéjar de Plasencia», pp. 313-318.

65 AGS. RGS, mayo de 1495, fol. 207; Ibidem.

66 Ladero Quesada, Los mudéjares de Castilla, p. 19.

67 AGS. Cámara de Castilla, CED, 9, fol. 13, doc. 1. Ver Ortego Rico, "Cristianos y mudéjares», pp. 290-291.

68 Redondo JaRillo, «La comunidad mudéjar de Plasencia», pp. 318-324. 
mezquita, intramuros, de nueva creación en los años finales de aquel siglo y, por tanto, a la que se referirían los documentos del siglo xvi, no hemos podido confirmarlo ${ }^{69}$. Tal vez la existencia de un yamur coronando la torre de la iglesia de San Esteban, lugar contiguo a la morería placentina, nos esté dando alguna pista.

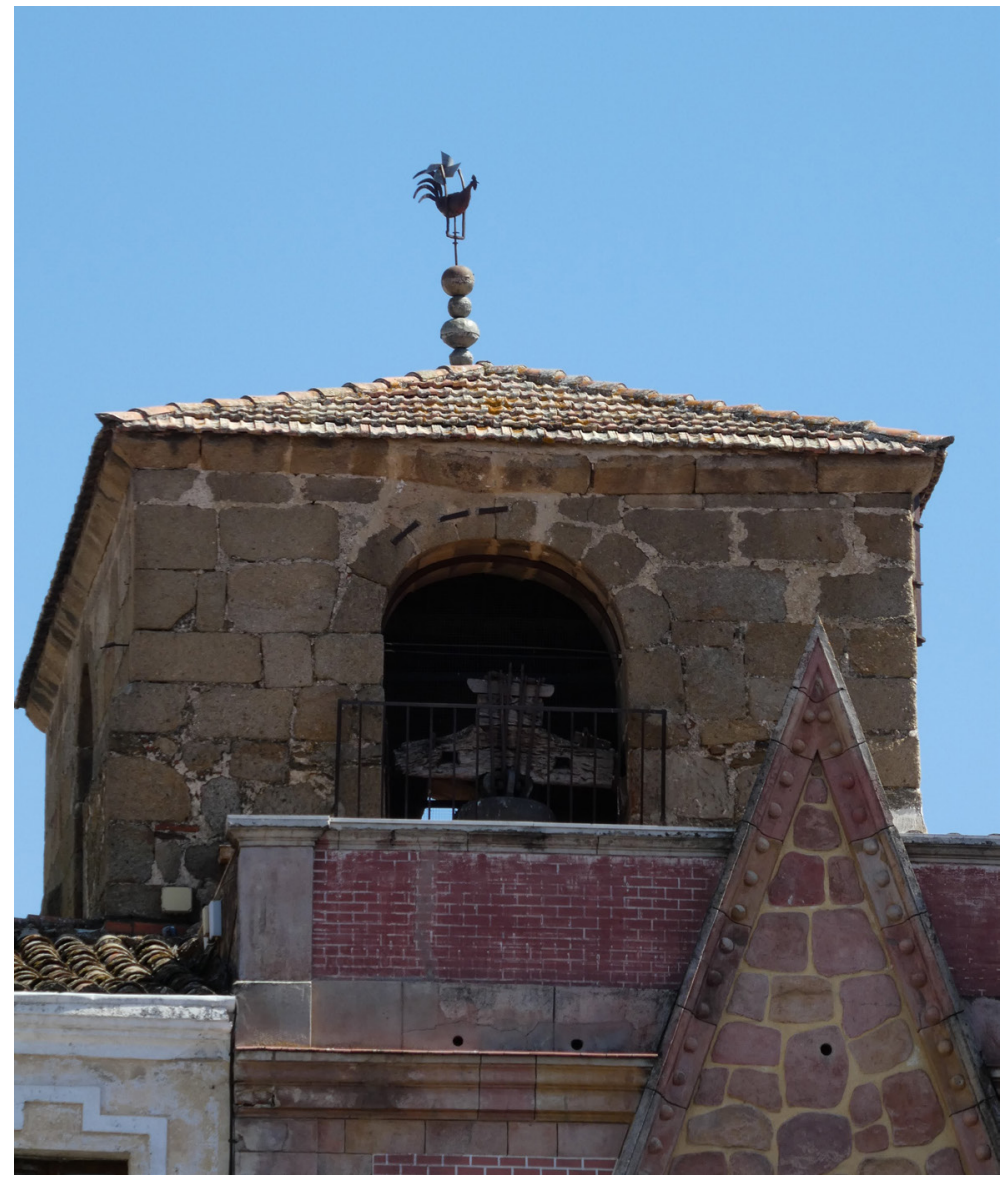

Figura 2. Yamur situado en la torre de San Esteban de Plasencia, probablemente procedente de la que fuera mezquita mudéjar placentina (fotografía: Juan Rebollo).

69 Durante nuestra estancia en la ciudad visitamos el interior de un inmueble privado de la calle Patalón, guiados por informaciones de tradición oral que nos aportó la archivera Esther Sánchez, quien nos trató de manera exquisita. Aunque no pudimos verlo ni analizarlo de manera completa, dicho inmueble había formado parte de un solar más extenso salpicado de «bodegones» y en alguno de ellos se había encontrado un «arco antiguo», según nos comentó su propietario, al que agradecemos su amabilidad. 


\subsubsection{Trujillo y Cáceres}

En la misma diócesis de Plasencia quedaron integradas las tierras andalusíes de Trujillo y Medellín tras sus conquistas en 1233 y 1234. Es probable que esta provincia eclesiástica placentina, al menos al sur del Tajo, hundiera su origen en el iqlimm o distrito provincial de al-Balāt, citado por al-Idrīsi ${ }^{-70}$. Sea como fuere, ambas plazas, trujillana y medellinense, habrían concentrado la mayor parte del poblamiento islámico del sector oriental extremeño en la última etapa andalusí ${ }^{71}$. Es lógico pensar, por tanto, que la mención, en plural, a las morerías de la diócesis placentina de finales del siglo XIII incluyera estas comunidades de musulmanes. En el caso de Trujillo se mantuvo como dominio realengo durante toda la Edad Media, a pesar de varios intentos de seńorialización. Si, siguiendo el argumento que exponíamos para Plasencia, es posible que se ejecutara, aunque muy transitoriamente, la orden de apartamiento de las minorías de 1412, podría haber sucedido lo mismo en el ámbito urbano trujillano. Noticias al respecto no hay.

De todos modos, hay constancia de judíos y moros viviendo en la plaza del arrabal (actual plaza Mayor de Trujillo) desde principios del siglo Xv e indicios sobre sus templos en los alrededores de la misma anteriores al confinamiento promulgado por los Reyes Católicos en $1480^{72}$. Lo que sabemos con seguridad es que la judería y la morería de la ciudad trujillana eran prácticamente limítrofes a finales de la Edad Media ${ }^{73}$. Ambos colectivos participaron en la expansión urbana producida en la segunda mitad del siglo $\mathrm{XV}$, sosteniendo actividades económicas tan importantes para la ciudad como el textil, en el caso judío, y la zapatería, en el caso mudéjar ${ }^{74}$. La calle nueva, hoy dividida en calle Tiendas (zona judía) y calle Margarita Iturralde (zona islámica) atravesaba los dos barrios, separados por la actual plaza del Azoguejo. Además, el peso demográfico de ambas minorías debió ser similar hasta la expulsión de los judíos. Para los moros, los castellanos de oro nos dan una aproximación de unos setenta vecinos pecheros en 1495-1496 y de unas veinte familias más en 1499-150175.

En cuanto a la mezquita, no hay dudas de su ubicación en los últimos años mudéjares. A raíz de la conversión de los musulmanes pasará a construirse en su solar el monasterio de San Francisco ${ }^{76}$, aún en pie. Con anterioridad, la información disponible nos remonta a verano de 1479 cuando se exime de huéspedes al templo islámico ${ }^{77}$. Estos

70 AL-IDrisi. La première géographie de l'Occident, trad. chevalier Jaubert, revisada por A. Nef. Paris: Flammarion, 1999, pp. 257 y 270.

71 Gilotte, Sophie. Aux marges d'al-Andalus. Peuplement et habitat en Estrémadure centre-orientale (VIII'-XIII siècles). Helsinki: Academia Scientiarum Fennica, 2010.

72 Rebollo Bote, «La comunidad mudéjar de Trujillo», p. 712.

73 Hervás, Marciano de. Judios y cristianos nuevos en la historia de Trujillo. Badajoz: autor, 2008, pp. 177 y ss.

74 Sánchez Rubio, M. Ángeles. El concejo de Trujillo y su alfoz en el tránsito de la Edad Media a la Edad Moderna. Badajoz: Universidad de Extremadura, 1993, pp. 410-413.

75 Con la aljama trujillana pechaban los moros de Cáceres; LAdERo Quesada, Los mudéjares de Castilla, p. 19.

76 AGS. RGS, febrero de 1503, fol. 310.

77 AGS. RGS, julio de 1479, fol. 23; y RGS, agosto de 1479, fol. 29. LADERo Quesada, «Los mudéjares de Castilla», pp. 105-106; OrTEgo Rico, «Elites y conflictividad», p. 508. 
documentos, uno de julio y otro de agosto del citado año, nos proporcionan el dato de que la mezquita se encontraba en el arrabal y disponía de corral, pero no mucho más. Tres ańos después, en 1482, a los moros dieron liçencia para que fagan su casa de oración en el muladar que está junto a la çerca de su apartamiento ${ }^{78}$. Esta casa de oración de nueva construcción se situaría en el barrio delimitado tras 1480, donde hoy se encuentra el monasterio franciscano. Desconocemos, sin embargo, el lugar exacto de la referida en 1479 -aunque también en el arrabal de la dicha çibdad-y si el motivo de su traslado se debió al confinamiento decretado o a consecuencias derivadas de la exención de huéspedes dada por la reina Isabel.

Por su parte, Cáceres no parece que contara con un grupo muy numeroso de musulmanes. Con total seguridad el mandato de apartamiento de las minorías de 1478 en la villa -con dos años de antelación respecto al general castellano-, aunque también aludía a los moros cacereños, estaba pensado fundamentalmente para apartar a la minoría judía, bastante más considerable desde el punto de vista demográfico y que había abandonado de manera progresiva la villa intramuros para asentarse en torno a la plaza ${ }^{79}$. La escasa relevancia de los mudéjares de Cáceres se entrevé del hecho de que no constituyeran aljama a aquellas alturas del siglo xv, ya que pechaban precisamente con la aljama de Trujillo. Acaso fueran lejanos descendientes de los moros siervos, una vez manumitidos, de los que habla el fuero cacereño. Solo un par de testimonios más tenemos registrado en relación con la población islámica. De un lado, un documento conservado en Simancas que nos informa de la tentativa de matar al alcaide de Cáceres por parte de los musulmanes de la villa ${ }^{80}$. De otro, la pervivencia hasta finales del siglo xIx del nombre de la calle de los Moros, desde entonces General Margallo. De existir alguna mezquita cacereña habría estado en algún punto de la misma calle, ¿en el lugar en el que en el siglo Xvi se construyó la iglesia de Santo Domingo?

\subsubsection{Badajoz, Medellín y otros lugares de la Baja Extremadura}

Ya hemos visto que, a excepción de los núcleos más o menos urbanos de la cuenca del Tajo (Alcántara, Trujillo o, ya en época castellana, Plasencia), la mayor parte del poblamiento islámico se concentró en la mitad sur de la región extremeña, tanto en su etapa andalusí como en la mudéjar. Sin embargo, a finales del siglo xv la presencia de musulmanes en la Baja Extremadura será meramente testimonial fuera de los ámbitos jurisdiccionales de las órdenes santiaguista y alcantarina. A pesar de que no conocemos más mezquitas que las comentadas más arriba, algunas noticias de interés sobre los moros nos pueden ayudar a seguir reconociendo espacios de identidad islámica en el territorio extremeño.

78 Archivo Municipal de Trujillo. Libro de Acuerdos, 1482-1484, Leg. 4.7, fol. 118r.

79 Sobre el apartamiento en Cáceres, principalmente para los judíos, véase MarTín NieTo, Serafín. «De sinagoga nueva a capilla de la Santa Cruz de Jerusalén del cacereño Palacio de la Isla». En XLII Coloquios Históricos de Extremadura. Trujillo: Asociación Cultural Coloquios Históricos de Extremadura, 2014, pp. 297-348.

80 AGS. RGS, abril de 1490, fol. 215. 
En Badajoz, otra de las aljamas extremeñas que se conformaron en el siglo XIII, llama la atención el escaso número de vecinos mudéjares que nos dan las fuentes fiscales a fines de la Edad Media, apenas seis familias pecheras en 1495 y una o dos en $1499-1500^{81}$. Los datos coinciden, además, con la mención que hace Rodrigo Dosma († 1599) cuando habla del episcopado de Alonso Manrique (1499-1516): Este prelado acabó de convertir a la religión cristiana la última casa de moros, que habian del antiguo trato quedado en Badajoz, y las personas conversas, de su apellido se dixeron Manrique ${ }^{82}$. Ante esta realidad demográfica mudéjar finisecular, no parece que fuera necesario poner en práctica la orden emanada de las Cortes de Toledo de 1480. No creemos, por tanto, que se conformara un barrio de moros en Badajoz. La aljama badajocense era en los últimos años del siglo xv una simbólica reminiscencia del pasado.

Medellín fue otra de las plazas islámicas de cierta entidad que encontraron los cristianos en las vegas del Guadiana. Aunque se retuvo como dominio de realengo en un principio, pronto pasaría de donación en donación a manos de señores ligados a la corte de los Trastámara hasta convertirse finalmente en un condado gobernado por los Portocarrero-Pacheco en la segunda mitad del Cuatrocientos. Perteneciente a la diócesis de Plasencia, albergaría con toda seguridad una de las comunidades musulmanas que se intuyen ya en el siglo XIII. Entre siete y diez vecinos pecheros conformaban su aljama en los últimos años mudéjares ${ }^{83}$, en tendencia decreciente según analizamos su contribución fiscal del servicio y medio servicio desde los años 60 del siglo $\mathrm{Xv}^{84}$. Esta decadencia posiblemente estuviera relacionada con el poder de atracción poblacional que ejercían las aljamas vecinas de los maestrazgos de Santiago y Alcántara. Las pocas familias musulmanas medellinenses de fines de siglo estarían asentadas en la calle de los moros (actual calle Margallo $)^{85}$ y allí debió situarse la mezquita, de la cual no tenemos referencia alguna. Tampoco tenemos certeza del cumplimiento de la orden de encerramiento, acaso porque, al igual que en Badajoz, no fuera necesario ejecutarla debido a la pequeñez de la aljama.

Como tampoco se precisaría el apartamiento en el resto de localidades bajoextremeñas de las que tenemos indicios de presencia mudéjar, cuyas limitadas noticias hacen presagiar una población musulmana muy testimonial. O no, porque en Burguillos del Cerro, seńorío de los Zúńiga de la Casa de Béjar y, por tanto, bajo el mismo gobierno que la ciudad de Plasencia durante un tiempo, el único dato disponible es el de tributación del servicio y medio servicio del año 1463 (3.000 maravedíes, que no es poco) ${ }^{86}$.

81 Ladero Quesada, Los mudéjares de Castilla, p. 19.

82 Dosma Delgado, Rodrigo. Discursos patrios de la real ciudad de Badajoz. Badajoz: Biblioteca Histórico-Extremeña, 1870 (primera edición 1601), p. 159.

83 Ladero Quesada, Los mudéjares de Castilla, p. 19.

84 Viñuales Ferreiro, Gonzalo. «El repartimiento del "servicio y medio servicio" de los mudéjares de Castilla en el último cuarto del siglo xv». Al-Qantara, 2003, vol. 24, n. ${ }^{\circ} 1$, pp. 179-202, aquí, p. 190; Rebollo Bote, «Morerías de Extremadura», p. 476.

85 Clemente Ramos, Julián. La Tierra de Medellin (1234-1450). Dehesas, ganadería y oligarquía. Badajoz: Diputación de Badajoz, 2007, pp. 126-127.

86 Viñuales Ferreiro, «El repartimiento», p. 194. Los moros de Burguillos no vuelven a aparecer en los registros contributivos del último tercio del siglo xv. 
Lo interesante de esta información fiscal es que la comunidad burguillana es citada como aljama y con ella, además, como hemos dicho más arriba, pechan los moros de Ribera del Fresno (en territorio santiaguista). Todo ello nos hace replantearnos la entidad y la organización de estas comunidades, que a veces son consideradas aljamas, y otras no, y que relacionan tributariamente mudéjares de jurisdicciones diferentes.

Muy cerca de Burguillos, en Zafra, señorío de los Suárez de Figueroa desde 1394, la única alusión a mudéjares es de época de Alfonso X y se refiere a su permanencia en la zona tras la conquista de Fernando III $^{87}$. Pero la conservación de un yamur islámico, expuesto actualmente en el Museo de Santa Clara, nos aporta un elemento más en relación con los musulmanes de la comarca y su lugar de oración. Dicho yamur procede del Hospital de San Miguel de la ciudad zafrense -edificio de estilo mudéjar de finales del siglo Xv- y coronó hasta hace pocos años la cúpula de la capilla del complejo hospitalario. A falta de estudios concretos sobre este tipo de elementos de gran simbolismo islámico, no podemos afirmar si su origen es andalusí o mudéjar. La común reutilización de los yamures en templos cristianos una vez se produce la desaparición teórica de la minoría religiosa musulmana nos lleva a plantear como hipótesis que el custodiado en Santa Clara proviniese de alguna mezquita cercana, ya fuera de la propia Zafra, de Burguillos, de Hornachos o de cualquier otra localidad vecina con pasado mudéjar.

Por último, en Olivenza, perteneciente entonces al reino de Portugal, también está atestiguada la presencia de algunas familias musulmanas, previsiblemente vinculadas a la aljama de Elvas.

\section{A MODO DE CONCLUSIÓN: LA REVALORIZACIÓN DE LOS ESPACIOS MUDÉJARES}

Esta primera aproximación sobre las mezquitas mudéjares extremeñas arroja conclusiones y reflexiones interesantes de cara a investigaciones futuras. En primer lugar, es cierto que disponemos de muy pocas certezas, apenas algunas noticias documentales que hemos reseñado y que nos llevan a plantear un sinfín de interrogantes. De momento, lo que sí podemos asegurar es que hubo continuidad de poblamiento islámico allí donde tenemos constancia de asentamiento almohade previo y de aljama mudéjar después. En segundo lugar, los musulmanes que permanecieron dejaron de rezar en sus antiguas mezquitas, que se convirtieron en iglesias, y se establecieron en los arrabales de sus villas y ciudades.

Esta reubicación islámica conformaría nuevos espacios de identidad, de los cuales tenemos algo más de información para finales de la Edad Media. Es entonces cuando asoman a la documentación las referencias a las mezquitas extremeńas que, siguiendo el patrón castellano del momento, parecen disponer de sala de oración, patio con pozo para las abluciones y un pequeño edificio anexo (casa del santero) que podría haber ejercido de casa del alfaquí. La existencia de varios -supuestos- yamures puede igualmente ponerse en relación con los lugares de oración islámica, aunque es pronto para poder determinar tal extremo y su adscripción mudéjar.

87 Alfonso X. Primera Crónica General, ed. Ramón Menéndez Pidal. Madrid: Gredos, 1955, p. 736. 
Nada sabemos sobre mezquitas en localidades como Magacela o Benquerencia de la Serena, y para el caso de Hornachos tan solo podemos deducir que hubo más de una y que sus restos podrían encontrarse en la ladera entre el actual pueblo y las ruinas del castillo, área de vecindario en época medieval. Badajoz también queda como incógnita. Conocemos, sin embargo, el lugar exacto donde estuvo la mezquita mudéjar en Trujillo (posterior convento de San Francisco), la situación aproximada de la de Mérida (zona de Morerías), la de Plasencia (en el arrabal de San Juan, al menos en 1463) y, con más dudas, las de Valencia de Alcántara (calle Mezquita), Medellín (calle Margallo) y Llerena (¿calle Morería y Herreros?).

Pero es en Alcántara, por ahora, donde más posibilidades tenemos para reconocer hoy el oratorio musulmán. Entre las calles Sancti Spíritus y Zapatería de la villa alcantarina está el inmueble que fue hospital y antes mezquita, de la que podrían conservarse elementos estructurales. Su estado de ruina podría servir de oportunidad para su estudio, ya que pudiera ser el único templo mudéjar llegado a nuestros días en Extremadura. El conocimiento y revalorización de los espacios de interés histórico (no turístico) son necesarios para la mejor comprensión del mudejarismo ibérico, tan olvidado en regiones como la extremeńa, más dada tradicionalmente a la recuperación -y, en ocasiones, reinvención- del «legado» judío.

\section{REFERENCIAS BIBLIOGRÁFICAS}

Alba Calzado, Miguel. «Ocupación diacrónica del área arqueológica de Morería (Mérida)». Mérida. Excavaciones Arqueológicas, 1994-1995, vol. 1, pp. 285-316.

Alba Calzado, Miguel. «Las producciones alfareras alentejano-extremeñas durante el Antiguo Régimen». Mérida. Ciudad y Patrimonio. Revista de Arqueología, Arte y Urbanismo, 1997, vol. 1, pp. 79-107.

Alba Calzado, Miguel. «Evidencias arqueológicas y fuentes escritas sobre el barrio alfarero de Mérida durante los siglos XV, XVI y XvII». En Actas das IV Jornadas de cerámica medieval e pos-medieval. 2008, pp. 143-155.

Alba Calzado, Miguel Â.; Feijoo Martínez, Santiago y Franco Moreno, Bruno. «Mérida islámica (s. VIII-IX): El proceso de transformación de la ciudad tardoantigua en una medina». XELB: Revista de Arqueología, Arte, Etnología e Historia, 2009, vol. 9, pp. 191-228.

Alfonso X. Primera Crónica General, ed. Ramón Menéndez Pidal. Madrid: Gredos, 1955.

AL-IDRISI. La première géographie de l'Occident, trad. chevalier Jaubert, revisada por A. Nef. Paris: Flammarion, 1999.

Bernal Estévez, Ángel. Mérida. Capital y encomienda de la Orden de Santiago (1490-1530). Badajoz: Diputación Provincial de Badajoz, 2013.

Bueno SÁnchez, María Luisa. «Fuga demonium, angeli pacis ingresus. El ritual litúrgico romanogalicano en el proceso de transformación de espacios sacros: de la mezquita a la iglesia (XIXIII)». En JimÉnez Martín, Alfonso (ed.). Simposium internacional sobre la catedral de Sevilla en el contexto del gótico final. La piedra postrera (2) Comunicaciones. Sevilla: Taller Dereçeo, 2007, pp. 261-280. 
Bustamante, Rosa; Cabezas, M. a Teresa y Gibello, Víctor M. «Moldura de cal de los arcos de herradura del aljibe de la Casa de las Veletas de Cáceres, España». Revista Electrónica ReCoPaR, 2009, vol. 6, pp. 3-13.

Clemente Ramos, Julián. La Tierra de Medellin (1234-1450). Dehesas, ganadería y oligarquía. Badajoz: Diputación de Badajoz, 2007.

DíAz GiL, Fernando. "Herederos de al-Asnām, aljamas de la Serena (siglos XIII-Xv)». En Actas de los III Encuentros de Estudios Comarcales Vegas Altas, La Serena y La Siberia. Magacela-La Coronada: Federación de Asociaciones Culturales de La Siberia, La Serena y Vegas Altas, 2010, pp. 87-107.

Dosma Delgado, Rodrigo. Discursos patrios de la real ciudad de Badajoz. Badajoz: Biblioteca Histórico-Extremeña, 1870.

Echevarría Arsuaga, Ana. "La "mayoría” mudéjar en León y Castilla: legislación real y distribución de la población (Siglos XI-XIII)». En la España Medieval, 2006, vol. 29, pp. 7-30.

Feijoo Martínez, Santiago y Alba Calzado, Miguel Á. «El sentido de la Alcazaba emiral de Mérida: su aljibe, mezquita y torre de señales». Mérida. Excavaciones Arqueológicas, 2002, vol. 8, pp. 565-586.

Franco Moreno, Bruno y Gibello Bravo, Víctor M. «La arqueología medieval en Extremadura. Estado de la cuestión». Boletín de Arqueología Medieval, 2012, vol. 16, pp. 67-120.

Gaibrois de Ballesteros, Mercedes. Historia del reinado de Sancho IV de Castilla. Madrid: Tip. de la Revista de Archivos, Bibliotecas y Museos, 1922-1928, 3 vols.

Galavís Bueno, Francisco. Consideraciones sobre el Barrio Gótico de Valencia de Alcántara. Badajoz: IMDEX Impresores, 2010.

Gilotte, Sophie. Aux marges d'al-Andalus. Peuplement et habitat en Estrémadure centre-orientale

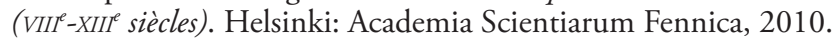

Gilotte, Sophie; González Cordero, Antonio y Souto Lasala, Juan Antonio. «Linscription d'époque omeyyade de la mosquée de Las Paredes (Logrosán, Espagne)». Archéologie Islamique, 2000, vol. 10, pp. 55-64.

González Rodríguez, Alberto. Hornachos, enclave morisco. Peculiaridades de una población distinta. Mérida: Editora Regional de Extremadura, 1990.

Hervás, Marciano de. Judíos y cristianos nuevos en la historia de Trujillo. Badajoz: autor, 2008.

Hervás, Marciano de (Seudónimo de Marciano Martín Manuel). Historia de los judios de Plasencia y su tierra. I, De los orígenes a la Inquisición. Siglos XII-XVIII. 2.a ed. Sevilla: Medios Audiovisuales (Libro electrónico), 2009.

JimÉNEZ GADEA, Javier. «Espacios y manifestaciones materiales de los musulmanes castellanos: presencias y ausencias de una minoría medieval». Edad Media. Revista de Historia, 2016, vol. 17, pp. 67-95.

Ladero Quesada, Miguel Ángel. Los mudéjares de Castilla en tiempo de Isabel I. Valladolid: Instituto Isabel la Católica de Historia Eclesiástica, 1969.

Ladero Quesada, Miguel Ángel. «Los mudéjares de Castilla en la Baja Edad Media». En Actas del I Simposio Internacional de Mudejarismo. Teruel: Centro de Estudios Mudéjares, 1981, pp. 339-390.

Ladero Quesada, Miguel Ángel. «Los mudéjares de Castilla en la Baja Edad Media». En Los mudéjares de Castilla y otros estudios de historia medieval andaluza. Granada: Universidad de Granada, 1989, pp. 11-132.

Ladero Quesada, Miguel Ángel. «Los mudéjares de Castilla cuarenta años después». En la España Medieval, 2010, vol. 33, pp. 383-424. 
López Dapena, Asunción. Cuentas y gastos (1292-1294) del rey D. Sancho IV el Bravo (12841295). Córdoba: Monte de Piedad y Caja de Ahorros de Córdoba, 1984.

Lora Serrano, Gloria. Ambroz, Ambrosía, Plasencia. Los nombres de una ciudad de la España medieval. Plasencia: Centro de Iniciativas y Turismo de la Comarca de Plasencia, 2016.

Martín Nieto, Dionisio Á. «Panorama histórico de la villa de Alcántara en el siglo XVI». En Noticias de Alcántara. Cáceres: Institución Cultural el Brocense, 2010, vol. 2, p. 53.

Martín Nieto, Serafín. "De sinagoga nueva a capilla de la Santa Cruz de Jerusalén del cacereño Palacio de la Isla». En XLII Coloquios Históricos de Extremadura. Trujillo: Asociación Cultural Coloquios Históricos de Extremadura, 2014, pp. 297-348.

Martín Nieto, Serafín y Martín Nieto, Dionisio Á. «Edificaciones religiosas de la villa de Alcántara». En Noticias de Alcántara. Cáceres: Institución Cultural el Brocense, 2010, vol. 2, p. 245.

Miranda Díaz, Bartolomé y Córdoba Soriano, Francisco de. Los moriscos de Magacela. Magacela: Ayuntamiento de Magacela, 2010.

Mogollón Cano-Cortés, Pilar. "Los alarifes moriscos y las realizaciones mudéjares en la villa de Hornachos». En Actas del IX Simposio Internacional de Mudejarismo. Mudéjares y moriscos, cambios sociales y culturales: Teruel: Instituto de Estudios Turolenses-Centro de Estudios Mudéjares, 2004, pp. 243-254.

MolÉnAT, Jean Pierre. «Â propos des noms et des mosquées des vieux mudéjars de Castille après l'édit de février 1502». En De mudéjares a moriscos: una conversión forzada. Teruel: Instituto de Estudios Turolenses, 2003, vol. 1, pp. 543-554.

MolÉnat, Jean Pierre. «Alfaquíes anonymes dans la Castille des Rois Catholiques. Une affaire de succession entre moros d'Estremadure dans les dernières années du Xve siècle». En EchEvarría Arsuaga, Ana (ed.). Biografias mudéjares o La experiencia de ser minoría. Madrid: Consejo Superior de Investigaciones Científicas, 2008, pp. 417-470.

MolÉnat, Jean Pierre. «Hornachos fin $\mathrm{Xv}^{\mathrm{e}}$-debut Xvi ${ }^{\mathrm{e}}$ siècles». En la España Medieval, 2008, vol. 31, pp. 161-176.

Monterde García, Juan Carlos. «La cuestión islámica en el fuero de Cáceres». Revista de Estudios Extremeños, 2010, vol. 66, n. ${ }^{\circ}$ 3, pp. 1145-1170.

Ortego Rico, Pablo. "Cristianos y mudéjares ante la conversión de 1502. Mercedes a moros. Mercedes de bienes de moros». Espacio, Tiempo y Forma. Serie III, Historia Medieval, 2011, vol. 24, pp. 279-318.

Ortego Rico, Pablo. «Elites y conflictividad en el seno de las aljamas mudéjares castellanas a fines de la Edad Media: exención tributaria y redes clientelares». Hispania, 2015, vol. 75, n.o 250, pp. 505-536.

Ortego Rico, Pablo. «La imagen de la minoría islámica castellana a través de las fuentes fiscales a fines de la Edad Media». Edad Media. Revista de Historia, 2016, vol. 17, pp. 33-66.

Rebollo Bote, Juan. «Espacios de nadie y de todos: Territorio y sociedad en la frontera andalusí al norte del Tajo extremeño (siglos VIII-XI)». Vegueta. Anuario de la Facultad de Geografía e Historia, 2015, vol. 15, pp. 185-209.

Rebollo Bote, Juan. «La comunidad mudéjar de Trujillo: algunas características de su aljama y morería». En XLIII Coloquios Históricos de Extremadura. Trujillo: Asociación Cultural Coloquios Históricos de Extremadura, 2015, pp. 691-716.

Rebollo Bote, Juan. «Morerías de Extremadura: espacios urbanos de vecindad islámica (mudéjar) a finales del siglo XV». Roda da Fortuna. Revista Eletrônica sobre Antiguidade e Medievo, 2015, vol. 4, n. ${ }^{\circ} 1-1$, pp. 456-475. 
Rebollo Bote, Juan. «En la frontera: el poblamiento islámico de Extremadura antes y después de la Raya con Portugal». En Amrán, Rica y Cortijo Ocaña, Antonio (eds.). Minorías en la España medieval y moderna: Asimilación y/o exclusión (siglos XV al XVII). Santa Barbara: Publications of eHumanista, 2018, pp. 61-75.

Rebollo Bote, Juan. "Recuerdos, olvidos y distorsiones sobre "lo islámico" y "lo judío" en Extremadura". En XLVII Coloquios Históricos de Extremadura dedicados a la Universidad de Salamanca. Trujillo: Asociación Cultural Coloquios Históricos de Extremadura, 2018, pp. 475-502.

Rebollo Bote, Juan. "Antes de "ser moriscos": datos e hipótesis sobre la etapa mudéjar de Hornachos». En X Jornadas de Historia de Almendralejo y Tierra de Barros, 2019, pp. 361-374.

Rebollo Bote, Juan. «La pervivencia de la identidad en las minorías: mudéjares y moriscos de Hornachos, Magacela y Benquerencia de la Serena». En Amrán, Rica y Cortijo Ocaña, Antonio (eds.). Jiménez de Cisneros: sus ideas y obra. Las minorias en España y América (siglos XV-XVIII). Santa Barbara: Publications of eHumanista, 2019, pp. 120-132.

Redondo Jarillo, M. ${ }^{a}$ Cristina. "La comunidad mudéjar de Plasencia durante el reinado de los Reyes Católicos». Medievalismo, 2013, vol. 23, pp. 291-341.

Rodríguez Blanco, Daniel. La Orden de Santiago en Extremadura en la Baja Edad Media (siglos XIV y XV). Badajoz: Editora Regional Extremeña-Diputación Provincial de Badajoz, 1985.

Sánchez Loro, Domingo. Historias placentinas inéditas. Primera parte. Vol. B. Cáceres: Institución Cultural El Brocense, 1983.

Sánchez Rubio, M.a Ángeles. El concejo de Trujillo y su alfoz en el tránsito de la Edad Media a la Edad Moderna. Badajoz: Universidad de Extremadura, 1993.

SoYer, François. The persecution of the Jews and Muslims of Portugal: King Manuel I and the End of Religious Tolerance (1496-7). Leiden-Boston: Brill, 2007.

VAldés, Fernando; Gussone, Martin y RüTenik, Tobias. «Die Transformation von Sakralbauten in Spanien: Voraussetzungen, Beispiel San Agustin in Badajoz». Beiträge zur Islamischen Kunst und Archäologie, 2008, vol. 1, pp. 123-134.

VAldés Fernández, Fernando. «La mezquita privada de 'Abd al-Rahman Ibn Marwan al-Yilliqi en la alcazaba de Badajoz». Cuadernos de Prehistoria y Arqueología de la Universidad Autónoma de Madrid, 1999, vol. 25, n. ${ }^{\circ}$ 2, pp. 267-290.

Villanueva Zubizarreta, Olatz. «Los mudéjares del norte de Castilla en vísperas del bautismo: expresiones religiosas de un Islam que no fue al-Andalus». eHumanista/Conversos, 2015, vol. 3, pp. 192-206.

Viñuales Ferreiro, Gonzalo. «El repartimiento del "servicio y medio servicio" de los mudéjares de Castilla en el último cuarto del siglo Xv». Al-Qantara, 2003, vol. 24, n. ${ }^{\circ}$ 1, pp. 179-202. 